\title{
Monitoring waste anesthetic gas in the pediatric postanesthesia care unit
}

\author{
Sam Kim, RPh • Timur Özelsel, MD (1) • Ban C. H. Tsui, MD
}

Received: 6 May 2016/Revised: 18 July 2016/Accepted: 21 July 2016/Published online: 29 July 2016

(c) Canadian Anesthesiologists' Society 2016

\section{To the Editor,}

Chronic exposure to waste anesthetic gas (WAG) and the potential threat of morbidity to medical personnel has been a subject of contentious debate for close to five decades. ${ }^{1}$ Awareness of the topic has led to substantial ventilation improvements in operating rooms (ORs). ${ }^{2}$ Postanesthesia care units (PACUs), however, are built differently from ORs with regard to ventilation standards. ${ }^{3}$

The National Institute for Occupational Safety and Health (NIOSH) set the recommended exposure limit for anesthetic gas. ${ }^{4}$ Specifically, NIOSH recommends that during a period of eight hours the concentration of nitrous oxide should not exceed 50 parts per million (ppm), and the halogenated ethers should not exceed $2 \mathrm{ppm}$. When both are used in the same setting, these values drop to $25 \mathrm{ppm}$ and $0.5 \mathrm{ppm}$, respectively.

Waste anesthetic gas in the PACU is generated by patients exhaling gases they were given during surgery. ${ }^{4}$ Here, we describe the daily measurement of WAG in a pediatric PACU over two non-consecutive weeks. These two time periods reflect two workloads (and thus patient loads) in the PACU, with a week in July representing a period of reduced OR activity and a week in October representing a period of regular OR activity.

Following approval of the University of Alberta Health Research Ethics Board (2014-06-27) a MIRAN ${ }^{\circledR}$ 205B Series SapphIRe portable ambient air analyzer (Thermo Electron Corporation, Waltham, MA, USA) was used to measure the sevoflurane concentration. Utilizing infrared

S. Kim, RPh · T. Özelsel, MD ( $ه)$ · B. C. H. Tsui, MD

Department of Anesthesiology and Pain Medicine, University

of Alberta, Edmonton, AB, Canada

e-mail: ozelsel@ualberta.ca spectroscopy, this analyzer has an accuracy of $\pm 10 \%$ and a detection limit of $0.04 \mathrm{ppm}$ for sevoflurane.

Because nitrous oxide was used as part of the mask induction and was demonstrable on a test measurement in the PACU, we assumed that the recommended exposure limit for sevoflurane was $0.5 \mathrm{ppm}$. During the week in July, there were a total of 99 cases, in 85 of which sevoflurane was used. Looking specifically at an eight-hour work period from 8:30 to $16: 30$, the recommended ceiling concentration of $0.5 \mathrm{ppm}$ was exceeded on each day for 87 , $69,114,75$, and $78 \mathrm{~min}$, respectively, from Monday to Friday (Figure). During the week in October, there were a total of 126 cases, in 112 of which sevoflurane was used. The ceiling concentration of $0.5 \mathrm{ppm}$ was exceeded for 243, 111, 66, 345, and $99 \mathrm{~min}$, respectively, from Monday to Friday over the same eight-hour period (Figure).

This study showed that, even in a modern PACU that was constructed according to current building standards, ambient air levels of WAG exceeded the recommendations. In addition, the WAG levels were related to the number of patients who received care. Although there is no evidence that these exposure levels place our staff at risk for longterm morbidity, these findings suggest an opportunity to reduce WAG exposure. Two paths can be taken to achieve permanent reduction. First, we, as anesthesiologists, could "pollute" less. That is, we could consider extubating patients with less volatile gases that remain in the patient's body or use intravenous anesthetics more often. Second, facilities management and engineering personnel could rethink the design of the PACU to improve the overall clearance of ambient air.

We hope that this communication brings renewed attention to WAG in PACUs. The recommended exposure limit has not changed since 1977, despite a significant change in the inhalational anesthetics used in 
Figure Pediatric PACU

sevoflurane concentration over time in $\mathrm{ppm}$
Pediatrics Post Anesthesia Care Unit Sevoflurane concentration (ppm) over Time

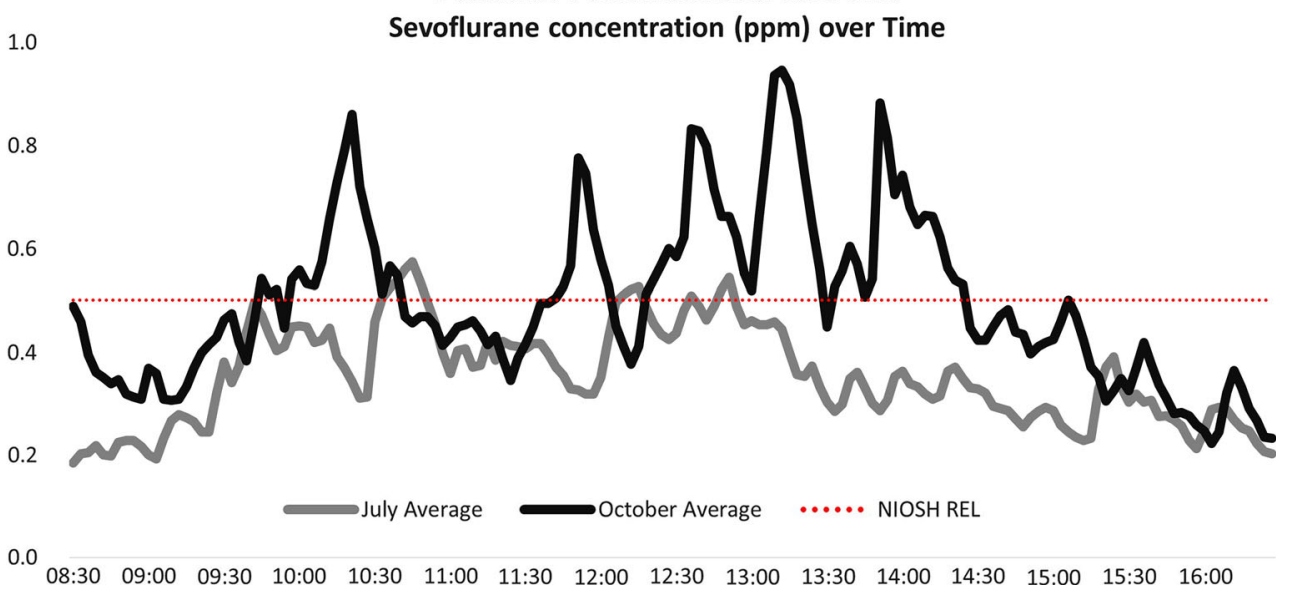

practice during that 40-year period. The most recent NIOSH update, which appeared in 1994, included a warning that researchers had not been able to identify a safe level of exposure for these new agents. ${ }^{5}$ Future research is required to understand the impact of WAG on health care workers and to develop methods to lower workplace exposure to WAG in the PACU.

Funding Dr. Tsui is supported by a Clinical Scholar Award from the Alberta Heritage Foundation for Medical Research (AHFMR). Dr. Tsui's research is supported by the Canadian Anesthesia Research Foundation.

Conflicts of interest None declared.

Editorial responsibility This submission was handled by Dr. Gregory L. Bryson, Deputy Editor-in-Chief, Canadian Journal of Anesthesia.

\section{References}

1. Saber AT, Hougaard KS. The Nordic Expert Group for Criteria Documentation of Health Risks from Chemicals. 141. Isoflurane, sevoflurane and desflurane. Arbete och Hälsa 2009; 43: 1-117. Available from URL: https://gupea.ub.gu.se/bitstream/2077/ 21413/1/gupea_2077_21413_1.pdf (accessed July 2016).

2. McGlothlin JD, Moenning JE, Cole SD. Evaluation and control of waste anesthetic gases in the postanesthesia care unit. J Perianesth Nurs 2014; 29: 298-312.

3. Wehmeyer MS, Moore B, Walton S, et al. Exhaled isoflurane from PACU patients may produce ambient concentrations exceeding NIOSH standards one hour after surgery. Anesthesiology 1996; 87: A361.

4. Center for Disease Control and Prevention. National Institute of Occupational Safety and Health. Criteria for a Recommended Standard: Occupational Exposure to Anesthetic Gases and Vapors. Cincinnati, OH, US Dept. of Health Education, and Welfare (DHEW), 1977, Publication number 77-140. Available from URL: http://www.cdc.gov/niosh/docs/1970/77-140.html (accessed July 2015).

5. Center for Disease Control and Prevention. National Institute for Occupational Safety and Health. NIOSH Pocket Guide to Chemical Hazards, DHHS (NIOSH) Publication No. 94-116, U.S. Government Printing Office, Washington, D.C., 1994. Available from URL: https://www.cdc.gov/niosh/npg/ (accessed July 2016). 